\title{
ДОСЛІДЖЕННЯ ТЕХНІКО - ЕКОНОМІЧНИХ ПОКАЗНИКІВ НАВАНТАЖУВАЧІВ
}

\begin{abstract}
У роботі викладено результати аналізу показників телескопічних навантажувачів вантажопідйомністю 2000 - 4000 кг, які найчастіше використовують для виконання навантажувально-розвантажувальних робіт у сільськогосподарських підприємствах. Сформовано базу характеристик різних моделей телескопічних навантажувачів. Для аналізу авторами обрано наступні характеристики: вантажопідйомність, маса, висота підйому стріли, потужність. Обрані параметри було згруповано у певні групи таким чином, щоб параметри кожної з груп в основному відображали зміни якої-небудь однієї із значущих характеристик вихідних функцій. 3 використанням кореляційного аналізу встановлено зв'язок між трьома параметрами, обраними для дослідження, а саме: вантажопідйомність і маса; маса та висота підйому; маса і потужність. Додатково розраховано параметри функціональних ознак - енергоємності та енергонасиченості. Для оцінювання впливу деяких факторів на обрані параметри функціональних ознак телескопічних навантажувачів - енергоємність $\mathrm{i}$ енергонасиченість виконано регресійний аналіз, що дозволило отримати багатофакторну математичну модель. Отримано рівняння регресії, які розкривають взаємозв'язок енергонасиченості та енергоємності і параметрів потужності та маси навантажувача. Встановлено, що найбільший вплив на енергонасиченість має потужність двигуна, відповідно на показник енергонасиченості - маса навантажувача.

Виконаний кореляційно-регресійний аналіз може бути покладений в основу процесу шляхів підвищення ефективності телескопічних навантажувачів для виконання сільськогосподарських робіт, а також проаналізувати вплив основних параметрів навантажувача на функціональні ознаки конструкцій: енергонасиченість, енергоємність, питому потужність, тощо.
\end{abstract}

Ключові слова: навантажувач, ефективність, параметри, кореляція, регресійний аналіз

\section{ВСТУП}

Ефективна організація виробничих процесів у сільському господарстві потребує механізації вантажно-розвантажувальних робіт, на які припадає до 40\% від усіх виробничих витрат [1]. Низький рівень механізації навантажувально - розвантажувальних і складських робіт у сільському господарстві призводить до значних простоїв техніки та, як наслідок, до зростання собівартості продукції.

Організація транспортування сільськогосподарських вантажів, які характеризуються значним різноманіттям, здійснюється 3 застосуванням підйомників, лебідок, кранів. Також широко застосовуються навантажувачі (фронтальні, грейферні, безперервної дії та ін.) кожен з яких має свої переваги і недоліки. В останній час у сільському господарстві все більшу нішу починають займати телескопічні навантажувачі. Це пояснюється їхньою універсальністю. Телескопічні навантажувачі поєднують в собі переваги підйомних кранів i навантажувачів, завдяки чому $\epsilon$ широко затребуваними.

На відміну від фронтальних навантажувачів телескопічні мають більшу висоту розвантаження та здатні виконувати більшу кількість різних операцій. Разом із ними використовують різне навісне обладнання: ківш, кранове устаткування, вили, тощо. Крім того, у телескопічних навантажувачів порівняно висока швидкість пересування, висока прохідність і мобільність.

У сільському господарстві телескопічні навантажувачі використовують не лише для виконання розвантажувально - навантажувальних робіт, а й для переміщення зеленої маси в траншеях у процесі закладання силосного корму.

Багатофункціональність навантажувачів пояснює великий попит на них. Але дані машини мають й недоліки, а саме: злам осей коліс, вихід з ладу трансмісії, злам гідроциліндрів. Це пояснюється значними навантаженнями які виникають через складні умови експлуатації. Крім того, за умови тривалих простоїв підлягають руйнуванню гумові елементи конструкції.

3 урахуванням вище означеного актуальним науково - практичним завданням $€$ аналіз техніко економічних показників телескопічних навантажувачів, що дозволить окреслити шляхи їхнього удосконалення, оцінювати конструктивну досконалість окремих моделей та обгрунтовано підбирати найбільш оптимальну за техніко - економічними та експлуатаційними характеристиками модель для потреб конкретного господарства. 


\section{АНАЛІЗ ЛІТЕРАТУРНИХ ДАНИХ ТА ПОСТАНОВКА ПРОБЛЕМИ}

Теоретичні передумови досліджень машин для навантажувально-розвантажувальних робіт викладено в роботах Абрамова С.В. [1], Лівшиця І.С. [2], Краснікова В.В. [3], Назарова Л.В. [4, 5], Базанова А.Ф. [6], Г.В. Родіонова, Л.Г. Фохта, Мініна В.В. [ 7 -10] та інших.

Мінін В.В. [9] виклав результати детального аналізу основних експлуатаційних і конструктивних характеристик універсального малогабаритного навантажувача, а також обгрунтував раціональні параметри навісного обладнання. Крім того автором розроблено класифікацію універсальних малогабаритних навантажувачів. Розроблено методику формування математичної моделі для оцінювання технічного рівня машин $[9,10]$.

Назаров Л.В., Разорьонов Л.В. [4] виклали результати теоретико-експериментальних досліджень стійкості малогабаритних колісних навантажувачів із бортовою системою повороту. Встановлено, що навантажувач починає втрачати стійкість в момент коли хоча б одне колесо машини відривається від опорної поверхні по якій здійснює свій рух.

Авторами розроблено методику розрахунку повороту малогабаритного навантажувача 3 бортовою системою повороту.

У роботі [5] авторами викладено результати теоретичного дослідження процесу руху малогабаритного навантажувача. В роботі наведено диференціальні рівняння руху навантажувача, в ході обгрунтування яких зроблено висновок про синусоїдальний характер автоколивань навантажувача, які проявляються під час виконання робіт.

Результати досліджень телескопічних навантажувачів викладено в роботах Вернера Є.А., Мандровського К.П., Тюріна Я.І. , Волкова В.І., Жилевича М. І. [11-16] та інших.

Вернер Є. А. [11] проаналізував ринок телескопічних навантажувачів й зробив висновок,що найбільш розповсюдженими $\epsilon$ навантажувачі кл. 3 т., 4 т. Автор також зазначає, що під час вибору приводу ходової частини є три варіанти. «Wandler» - класичний привод, який підходить для всіх типів навантажувачів. Перевага даного приводу в його нескладній та надійній конструкції. «Powershift» привод, який дозволяє змінювати ходові ступені без зупинки руху. «Hydrostat», який дозволяє запускати двигун на високій частоті обертання без збільшення потужності гідросистеми.

Тюрин Я. І., Мандровський К.П.[12] дослідили динамічні процеси, які відбуваються у фронтальному навантажувачі методом математичного моделювання механічних систем.

Авторами розроблено алгоритм і методика вирішення задачі оптимізації переміщення вантажу колісним фронтальним навантажувачем.

Дослідження Волкова В.І., Жилевича М. I. [13-14] присвячено гідравлічним системам. Зокрема в роботі [13] розроблено математичну модель для визначення взаємного положення ланок механізму підйому стріли навантажувача 3 гідравлічним приводом робочого обладнання, отримано математичні залежності які дозволяють оцінити ряд силових факторів, що діють на стрілу під час її переміщення. Базуючись на результатах виконаних досліджень можна обрати раціональні значення конструктивних параметрів і виконати параметричний синтез привода.

Як показав результат аналізу літературних джерел, в основному, дослідження стосуються малогабаритних універсальних навантажувачів. Питання експлуатації, оцінювання техніко економічних показників телескопічних навантажувачів практично не досліджувались.

3 врахуванням вище зазначеного сформулюємо мету і задачі нашого дослідження.

\section{ЦІЛЬ ТА ЗАДАЧІ ДОСЛІДЖЕННЯ}

Оцінювання взаємозв'язків основних показників техніко - економічної ефективності телескопічних навантажувачів.

Для досягнення даної мети потрібно було вирішити наступні задачі:

- сформувати базу характеристик різних моделей телескопічних навантажувачів;

- встановити математичні залежності, які розкривають взаємозв'язок між параметрами;

- виявити найбільш вагомі фактори впливу на такі показники як енергоємність та продуктивність телескопічного навантажувача.

\section{РЕЗУЛЬТАТИ ДОСЛІДЖЕНЬ}

3 метою вирішення поставлених задач нами було сформовано базу даних параметрів телескопічних навантажувачів BOBCAT, MANITOU, JCB, Claas, Faresin. Обирали навантажувачі вантажопідйомністю 2500 - 4000 кг, які найбільше використовують у сільському господарстві.

Для аналізу обрано наступні характеристики:

вантажопідйомність (X1) - Q, кг;

- маса машини (X2) -m, кг; 
- висота підйому вантажу (X3) -h, м;

- потужність двигуна (X4)- N, кВт;

Додатково розраховано функціональні параметри енергонасиченість (Y1) $E=\frac{N}{m}$ та енергоємність (Y2) $N_{Q}=\frac{N}{Q}$.

Для оцінювання впливу деяких характеристик на обрані нами параметри функціональних ознак телескопічних навантажувачів - енергоємність i енергонасиченість виконано кореляційнорегресійний аналіз, що дозволило отримати багатофакторну математичну модель.

Кореляційно-регресійний аналіз є класичним методом стохастичного моделювання та дозволяє виконати кількісну оцінку взаємозалежностей між ознаками досліджуваного об'єкту. Основна задача, яка може бути вирішена з застосуванням кореляційно-регресійного аналізу, це кількісне оцінювання зв'язку між двома ознаками, а також між результуючою функцією та факторними ознаками.

Аналіз виконувався з використанням програми Microsoft Excel у такій послідовності.

1. Дослідили однорідність даних за кожним фактором.

2. За методом кореляційних плеяд [15] виключили несуттєві фактори.

У ході проведення дослідження ми обрали перелік характеристик, які, на наш погляд, впливають на вихідні функції - показники енергоємності та енергонасиченості. Але не всі обрані характеристики $є$ значущими й такими, що визначають величину вихідних функцій. Тому обрані параметри було згруповано у певні групи таким чином, щоб параметри кожної з групи в основному відображали зміни якої-небудь однієї із значущих характеристик вихідних функцій. Наявність такої групи дає можливість оцінити значення кожної значущої характеристики тільки по одному або декількох параметрах відповідної групи, т. т. зменшити кількість інформації, необхідної для достатньо повного опису вихідної функції.

За критерій кількісного оцінювання взаємозв'язку (залежності) між параметрами ми обрали коефіцієнт кореляції або міру зв'язків.

Згідно [16] два параметри коррелируют між собою додатньо якщо між ними існує пряме, односпрямоване співвідношення. Два параметри коррелюють між собоювідємно, якщо між ними існує зворотнє, різнобічне співвідношення.

Визначали коефіцієнти парної кореляції $\mathrm{r}$, який показав взаємозв'язок між досліджуваними величинами. Коефіцієнт кореляції може набувати значень від -1 до 1. Чим ближче значення коефіцієнта до 0, тим зв'язок слабший. Якщо коефіцієнт кореляції рівний 0 , це свідчить про відсутність зв'язку, а при 1 чи -1 - зв'язок максимально жорсткий. Загалом, прийнято вважати, що зв'язок сильний за умови значення модуля коефіцієнта кореляції від 0,6 і вище.

Знак коефіцієнта кореляції вказує на тип зв'язку, коли він додатній, то зв'язок прямий, коли від’ємний - зворотній [16]. Коефіцієнт кореляції обчислювали в програмі Excel. Нижче наведемо залежність для визначення коефіцієнту кореляції з метою наглядного віцдображення змісту обчисленої величини:

$$
r=\frac{\sum_{i=1}^{n}\left(x_{i}-\bar{x}\right) \cdot\left(y_{i}-\bar{y}\right)}{\sqrt{\sum_{i=1}^{n}\left(x_{i}-\bar{x}\right)^{2} \cdot \sqrt{\sum_{i=1}^{n}\left(y_{i}-\bar{y}\right)^{2}}}}
$$

де $x_{i} ; y_{i}$ - значення досліджуваної величини і-го порядку,

$\bar{x}_{\mathrm{i}} \bar{y}$ середні значення даних величин:

$$
\bar{x}=\frac{\sum_{i=1}^{n} x_{i}}{n} \text { та } \bar{y}=\frac{\sum_{i=\mathbf{1}}^{n} y_{i}}{n}
$$

$n$ - кількість варіантів значень досліджуваних величин.

3. Застосувавши регресійний аналіз виконали математичне моделювання, отримавши модель, що розкриває функціональні залежності між енергоємностю i енергонасиченостю та іншими характеристиками навантажувачів.

Регресійний аналіз включав наступні кроки:

- визначення викидів;

- виключення параметрів із найменшим впливом на вихідну функцію;

- складання моделі вихідної функції. 


\section{ОБГОВОРЕННЯ РЕЗУЛЬТАТІВ ДОСЛІДЖЕННЯ}

3 метою проведення дослідження зібрано інформацію щодо параметрів 35-ти моделей телескопічних навантажувачів.

3 використанням пакету програми Excel визначили коефіцієнти парної кореляції. Результати подано нижче у табл. 1.

Таблиця 1 - Отримані значення коефіцієнтів парної кореляції

\begin{tabular}{|c|c|c|c|c|}
\hline & $\mathrm{X} 1$ & $\mathrm{X} 2$ & $\mathrm{X} 3$ & $\mathrm{X} 4$ \\
\hline $\mathrm{X} 1$ & 1,0 & & & \\
\hline $\mathrm{X} 2$ & 0,7239 & 1,0 & & \\
\hline $\mathrm{X} 3$ & 0,4931 & 0,8723 & 1,0 & \\
\hline $\mathrm{X} 4$ & 0,4147 & 0,6379 & 0,3203 & 1,0 \\
\hline
\end{tabular}

Ранжуваня за впливом факторів (параметрів) подано на рис. 1 у вигляді кореляційного графа.

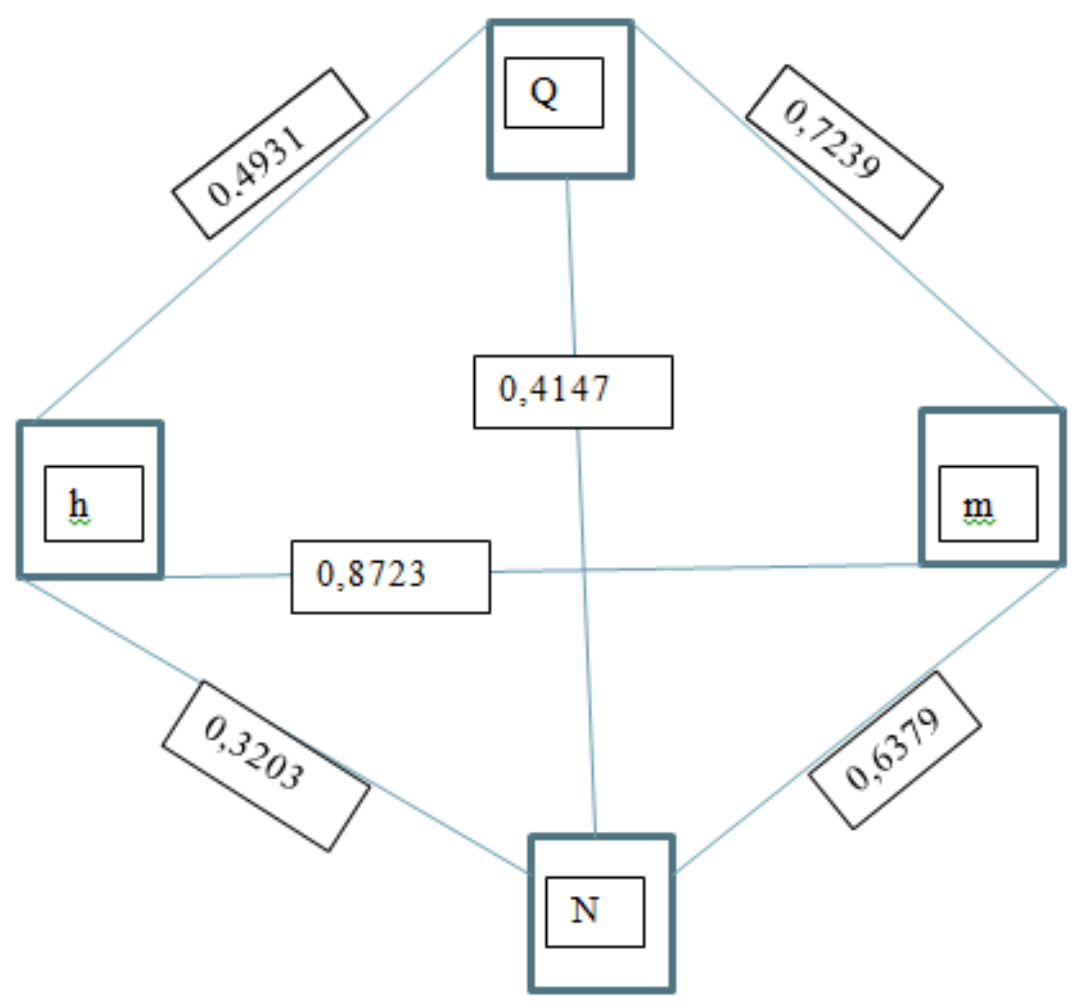

Рисунок 1 - Кореляційний граф

Задаємось порогом кореляції 0,45 і сформуємо кореляційні плеяди (рис. 2).
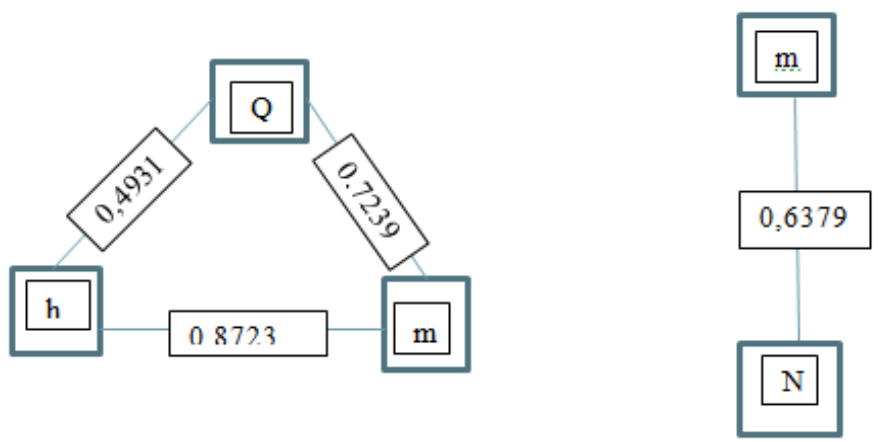

Рисунок 2 - Кореляційні плеяди за умови, що поріг становить 0,45

Отримані результати виявили значний зв'язок між трьома факторами, обраними для дослідження, а саме: 
- вантажопідйомність і маса $(0,7239)$;

- маса та висота підйому $(0,8723)$;

- маса і потужність $(0,6379)$.

Кожен із зазначених функціональних зв'язків можна пояснити фізичним змістом даних показників.

Базуючись на результатах кореляційного аналізу виконано регресійний аналіз метою якого $\epsilon$ отримання регресійної залежності між досліджуваними величинами для встановлення фактичного впливу кожного з факторів на функції енергонасиченості (Y1) та енергоємності (Y2).

Отримано рівняння регресії, яке розкриває взаємозв'язок енергонасиченості та параметрів потужності $\left(\mathrm{X}_{4}\right)$ і маси навантажувача $\left(\mathrm{X}_{3}\right)$

$$
Y_{1}=64,5 x_{4}+0,039 x_{3}
$$

Дане рівняння показує, що найбільший вплив на енергонасиченість має потужність двигуна.

Рівняння регресії, яке розкриває взаємозв’язок енергоємності та параметрів потужності $\left(\mathrm{X}_{4}\right) \mathrm{i}$ маси навантажувача $\left(\mathrm{X}_{3}\right)$ :

$$
Y_{2}=101,0 x_{3}+79,79 x_{4}
$$

Як бачимо на енергоємність найбільший вплив має маса навантажувача. За умови зменшення маси навантажувача можна зменшити енергоємність і, відповідно, металоємність машини.

\section{ВИСНОВКИ}

Виконаний кореляційно-регресійний аналіз дозволить вести пошук шляхів підвищення ефективності телескопічних навантажувачів для виконання сільськогосподарських робіт, а також проаналізувати вплив основних параметрів навантажувача на функціональні ознаки конструкцій: енергонасиченість, енергоємність, питому потужність, тощо.

\section{ПЕРЕЛІК ДЖЕРЕЛ ПОСИЛАННЯ}

1. Абрамов С.В. Фронтальные погрузчики: Учебное пособие. Караганда. : Карагандинский политехнический институт, 1990. - 154 с.

2. Лившиц В.Н. Системный анализ экономических процессов на транспорте. М.: Транспорт, $1986,-228 \mathrm{c}$.

3. Красников В.В. Подъемно-транспортные машины. М.: Колос, 1981. -263 с.

4. Назаров Л. В. Динамические процессы при развороте малогабаритного погрузчика с бортовой системой поворота/Л.В. Назаров, Л.В. Разаренов// Сборник научных трудов «Вестник Харьковского национального автомобильно-дорожного университета»., 2007. - С. 180-183.

5. Назаров Л.В.Особенности поворота малогабаритного погрузчика типа ПМТС 1200/ Л.В. Назаров., В.П. Истомин., Л.В. Разаренов // Вестник ХНАДУ. - 2004. - Вып. 25. - С. 54-58.

6. Базанов, А.Ф. Самоходные погрузчики /А.Ф. Базанов, Г.В. Забегалов. -М.: Машиностроение, 1979. $-408 \mathrm{c}$.

7. Родионов, Г.В. Усилия, действующие на ковш при черпаниискальных пород /Г.В. Родионов//Тр. горн. геол. ин-та. -Новосибирск, 1957. -№19. - С. 47-54.

8. Фохт, Л.Г. Машины и оборудование для погрузочно-разгрузочных работ /Л.Г. Фохт; под ред. С.П. Епифанова - М. :Стройиздат, 1982. - 240 с.

9. Минин В. В. Исследование влияния параметров малогабаритных машин на их технический урівень/ В. В., Минин, Г.С. Гришко // Транспортные средства Сибири: сб. науч. тр. / отв. ред. С.П. Ереско. Красноярск, 1999. Вып. 5. - С. 184-186.

10. Минин В.В. Концепция повышения эффективности универсальных малогабаритных погрузчиков: монография. Красноярск: Сибирский федеральный ун-т, 2012. - 304 с.

11. Вернер Е. А. Краткое описание конструкции, результаты испытаний и техническая характеристика четырех новых навесных телескопических погрузчиков. (ФРГ)]. Vier Teleskoplader im DLZ-Vergleich. JCB 530 Farm Special - John Deere 3400 - Manitou MLT 730 TLS - Merlo 33. 7 KT // DLZ Agrarmag. AgroBonus. - 2002. - Jg.53,N 1. - S. 64-73.

12. Тюрин Я.И. Подходы к осуществлению математического моделирования многокомпонентных механических систем (на примере фронтального погрузчика с телескопическим рабочим оборудованием)/ Я.И. Тюрин, К.П. Мандровский// Сб. трудов Московского госуд.автомобильно-дорожного университета, 2019. - С.59 - 62. 
13. Волков В.И. Тенденции развития мобильной гидравлики для фронтальних и телескопических погрузчиков (на примере продукции фирмы BOSCH REXROTH).

14. Жилевич М.И. Анализ нагруженности гидроцилиндра механизма подъема телескопической стрелы погрузчика/М.И. Жилевич, П.Н. Кишкевич, А.А. Зубрицкиц//Сб.трудов Беларусского нац.-го техн. ун.-та, 2017. - С.31-34. №9.

15. Терентьев, П. В. Метод корреляционных плеяд / П. В. Терентьев // Вестник ЛГУ. - 195. -

16. Кендел М. Ранговые корреляции. М.: Статистика, 1975. - 216 с.

\section{REFERENCES}

1. Abramov S.V. Frontal'nye pogruzchiki: Uchebnoe posobie. Karaganda. : Karagandinskij politekhnicheskij institut, 1990. - $154 \mathrm{~s}$.

2. Livshic V.N. Sistemnyj analiz ehkonomicheskikh processov na transporte. M.: Transport, 1986, $228 \mathrm{~s}$.

3. Krasnikov V.V. Pod"emno-transportnye mashiny. M.: Kolos, 1981. - 263 s.

4. Nazarov L. V. Dinamicheskie processy pri razvorote malogabaritnogo pogruzchika s bortovoj sistemoj povorota/L.V. Nazarov, L.V. Razarenov// Sbornik nauchnykh trudov «Vestnik Khar'kovskogo nacional'nogo avtomobil'no-dorozhnogo universitetA»., 2007. - S. 180-183.

5. Nazarov L.V.Osobennosti povorota malogabaritnogo pogruzchika tipa PMTS 1200/ L.V. Nazarov., V.P. Istomin., L.V. Razarenov // Vestnik KHNADU. - 2004. - Vyp. 25. - S. 54-58.

6. Bazanov, A.F. Samokhodnye pogruzchiki /A.F. Bazanov, G.V. Zabegalov. -M.: Mashinostroenie, 1979. $-408 \mathrm{~s}$.

7. Rodionov, G.V. Usiliya, dejstvuyushchie na kovsh pri cherpaniiskal'nykh porod /G.V. Rodionov//Tr. gorn. geol. in-ta. -Novosibirsk, 1957. -№19. - S. 47-54.

8. Fokht, L.G. Mashiny i oborudovanie dlya pogruzochno-razgruzochnykh rabot/L.G. Fokht; pod red. S.P. Epifanova - M. :Strojizdat, 1982. - 240 s.

9. Minin V. V. Issledovanie vliyaniya parametrov malogabaritnykh mashin na ikh tekhnicheskij uriven'/ V. V., Minin, G.S. Grishko // Transportnye sredstva Sibiri: sb. nauch. tr. / otv. red. S.P. Eresko. Krasnoyarsk, 1999. Vyp. 5. - S. 184-186.

10. Minin V.V. Koncepciya povysheniya ehffektivnosti universal'nykh malogabaritnykh pogruzchikov: monografiya. Krasnoyarsk: Sibirskij federal'nyj un-t, 2012. - 304 s.

11. Verner E. A. Kratkoe opisanie konstrukcii, rezul'taty ispytanij i tekhnicheskaya kharakteristika chetyrekh novykh navesnykh teleskopicheskikh pogruzchikov. (FRG)]. Vier Teleskoplader im DLZVergleich. JCB 530 Farm Special - John Deere 3400 - Manitou MLT 730 TLS - Merlo 33. 7 KT // DLZ Agrarmag. AgroBonus. - 2002. - Jg.53,N 1. - S. 64-73.

12. Tyurin YA.I. Podkhody $\mathrm{k}$ osushchestvleniyu matematicheskogo modelirovaniya mnogokomponentnykh mekhanicheskikh sistem (na primere frontal'nogo pogruzchika s teleskopicheskim rabochim oborudovaniem)/ YA.I. Tyurin, K.P. Mandrovskij// Sb. trudov Moskovskogo gosud.avtomobil'nodorozhnogo universiteta, 2019. - S.59-62.

13. Volkov V.I. Tendencii razvitiya mobil'noj gidravliki dlya frontal'nikh i teleskopicheskikh pogruzchikov (na primere produkcii firmy BOSCH REXROTH).

14. Zhilevich M.I. Analiz nagruzhennosti gidrocilindra mekhanizma pod"ema teleskopicheskoj strely pogruzchika/M.I. Zhilevich, P.N. Kishkevich, A.A. Zubrickic//Sb.trudov Belarusskogo nac.-go tekhn. un.-ta, 2017. - S.31-34.

15. Terent'ev, P. V. Metod korrelyacionnykh pleyad / P. V. Terent'ev // Vestnik LGU. - 195. - №9.

16. Kendel M. Rangovye korrelyacii. M.: Statistika, 1975. - $216 \mathrm{s.}$

\section{Puts, P. Meles. Research of technical and economic indicators of loaders.}

The article deals with the results of the analysis of indicators of telescopic loaders with a carrying capacity of $2000-4000 \mathrm{~kg}$. These indicators are most often used to perform loading and unloading operations in agricultural enterprises. The base of characteristics of various models of telescopic loaders was formed. The following characteristics: load capacity, weight, boom lift height, power were selected by the authors for analysis. The selected parameters were grouped into specific groups so that the parameters of each of the groups mainly reflect changes in any one of the significant characteristics of the original functions. The connection with the use of correlation analysis has been established between the three parameters selected for research, namely: load capacity and weight; weight and height of lifting; weight and 
power. The parameters of the functional characteristics of energy intensity and energy saturation have been calculated additionally. Regression analysis was used to assess the influence of some factors on the selected parameters of the functional characteristics of telescopic loaders (energy intensity and energy saturation). This analysis made it possible to obtain a multifactor mathematical model. Regression equations have been obtained that reveal the relationship between energy saturation and energy intensity and power parameters and weight of the loader. It is established that the greatest influence on energy saturation has the engine power, on the indicator of energy saturation - the weight of the loader, respectively.

Correlation-regression analysis can be based on the process of improving the efficiency of telescopic loaders for agricultural work. The influence of the main parameters of the loader on the functional features of structures: energy saturation, energy intensity, specific power, etc. is analyzed in the article.

Key words: loader, efficiency, parameters, correlation, regression analysis

ПУЦЬ Віталій Степанович, кандидат технічних наук, завідувач кафедри галузевого машинобудування, Луцький національний технічний університет. e-mail: putsvs@ukr.net, https://orcid.org/0000-0003-3164-6173.

МЕЛЕСЬ Павло Петрович, аспірант, Луцький національний технічний університет. e-mail: pavlomeles.com@gmail.com.

Vitaly PUTS, PhD in Engeneering, head of the of Industrial Engineering Departmen, Lutsk National Technical University. e-mail: putsvs@ukr.net, https://orcid.org/0000-0003-3164-6173.

Pavlo MELES, Postgraduate Student, Lutsk National Technical University. e-mail: pavlomeles.com@gmail.com.

DOI 10.36910/automash.v2i17.643 